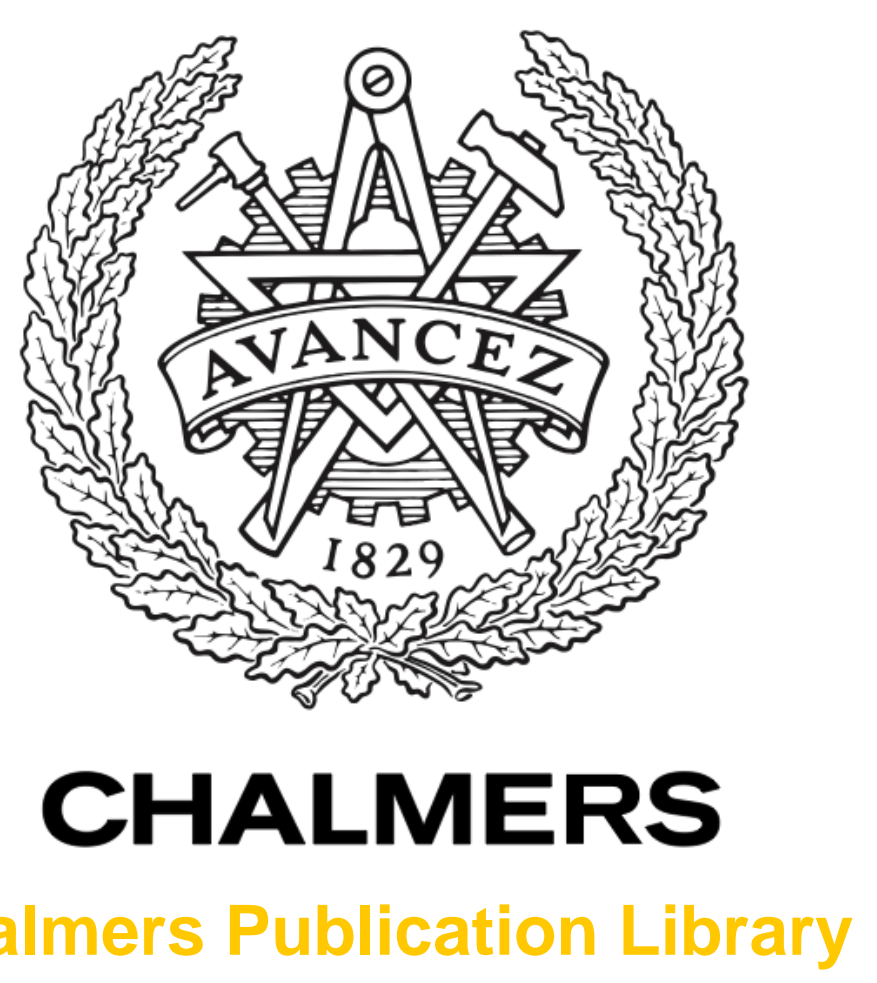

Chalmers Publication Library

\title{
Model-based diesel Engine Management System optimization for transient engine operation
}

This document has been downloaded from Chalmers Publication Library (CPL). It is the author's version of a work that was accepted for publication in:

Control Engineering Practice (ISSN: 0967-0661)

Citation for the published paper:

Grahn, M. ; Johansson, K. ; McKelvey, T. (2014) "Model-based diesel Engine Management System optimization for transient engine operation". Control Engineering Practice, vol. 29 pp. 103-114.

http://dx.doi.org/10.1016/j.conengprac.2014.04.005

Downloaded from: http://publications.lib.chalmers.se/publication/198403

Notice: Changes introduced as a result of publishing processes such as copy-editing and formatting may not be reflected in this document. For a definitive version of this work, please refer to the published source. Please note that access to the published version might require a subscription.

Chalmers Publication Library (CPL) offers the possibility of retrieving research publications produced at Chalmers University of Technology. It covers all types of publications: articles, dissertations, licentiate theses, masters theses, conference papers, reports etc. Since 2006 it is the official tool for Chalmers official publication statistics. To ensure that Chalmers research results are disseminated as widely as possible, an Open Access Policy has been adopted.

The CPL service is administrated and maintained by Chalmers Library. 


\title{
Model-based diesel Engine Management System optimization for transient engine operation
}

\author{
Markus Grahn $^{\mathrm{a}, \mathrm{b}, *}$, Krister Johansson ${ }^{\mathrm{a}}$, Tomas McKelvey ${ }^{\mathrm{b}}$ \\ a Volvo Car Corporation, SE-405 31 Gothenburg, Sweden \\ ${ }^{\mathrm{b}}$ Department of Signals and Systems, Chalmers University of Technology, SE-412 96 Gothenburg, Sweden
}

\section{A R T I C L E I N F O}

\section{Article history:}

Received 26 September 2013

Accepted 14 April 2014

\section{Keywords:}

Diesel engine

Engine control

Fuel consumption

Emissions

Optimization

Transient

\begin{abstract}
A B S T R A C T
A recently developed strategy to calculate set points for controllable diesel engine systems is described, further developed, and evaluated. The strategy calculates set points with an aim to minimize fuel consumption for a given dynamic vehicle driving cycle, while keeping accumulated emissions below given limits. The strategy is based on existing methodology for steady-state engine operation, but extended to handle transient effects in the engine caused by dynamics in the engine air system. Using the strategy, set points for the complete operating range of the engine can be calculated off-line and stored in an Engine Management System, hence set points can be derived for any (steady-state or transient) driving scenario. The strategy has been evaluated using a simulation model of a complete diesel engine vehicle system. The model estimates fuel consumption, $\mathrm{NO}_{\mathrm{X}}$, and soot emissions for a dynamic vehicle driving cycle depending on set points for boost pressure, oxygen fraction in the intake manifold, and injection timing, throughout the simulation. Using this simulation model, the strategy has been shown to decrease fuel consumption for the New European Driving Cycle with 0.56\%, the Federal Test Procedure with $1.04 \%$, and the Japanese JC08 cycle with $0.84 \%$ compared to a strategy based on steady-state engine operation.
\end{abstract}

c 2014 Elsevier Ltd. All rights reserved.

\section{Introduction}

A modern passenger car diesel engine is complex with several controllable systems. Due to the many controllable systems and the well-known trade-off between fuel consumption and emissions, it is a challenging and time consuming process to define settings in the Engine Management System (EMS) for all controllable engine systems to achieve optimal operation of the engine. Settings should be defined such that fuel consumption for a dynamic vehicle driving cycle is minimized while accumulated emissions are below given limits. The controllable systems in an engine can be divided into two main categories; systems that influence the air path and systems that influence the fuel path of the engine. A main difference between these categories is the dynamic behavior of the air path, i.e. important variables such as boost pressure and oxygen fraction are governed by differential equations and hence depend on past control inputs. A diesel engine is normally equipped with a turbo system. The turbo system is a rotational system that is driven by the energy in the exhaust gases. Due to the moment of inertia of the compressor,

* Corresponding author at: Department of 97544 VCG PV3B, Volvo Car Corporation, SE-405 31 Gothenburg, Sweden. Tel.: +46 31772 1395; fax: +46 31180976. E-mail address: mgrahn1@volvocars.com (M. Grahn). turbine, and turbine shaft, there are dynamics in this system. The air system also consists of pipes and manifolds with certain volumes, and dynamics govern the emptying and filling of these volumes (Heywood, 1988).

The performance of an engine in a given application is evaluated by driving a complete vehicle according to a pre-defined cycle, while measuring total fuel consumption and emissions for the complete cycle (Timothy, 2012). This means that to be able to find optimal control strategies and set points for an engine, the complete vehicle system needs to be considered. Optimal EMS settings for an engine in one vehicle application are most likely not the optimal settings for the same engine in another vehicle application, i.e. in a vehicle with different mass, different drag coefficient, etc.

Currently, engine control is mostly based on non-linear feedforward control implemented using two-dimensional bilinear interpolation maps, commonly denominated as grid maps (Robert Bosch $\mathrm{GmbH}, 2003)$. The inputs to these maps are the injected fuel amount and the current engine speed, and the outputs are set points for the various controllable engine quantities, e.g. boost pressure, exhaust gas recirculation (EGR) rate, and injection timing. Feedback controllers are used to obtain the predefined settings for the air path. The values in the grid maps are typically calibrated based on steady-state engine operation. Methods for this are well developed and described in the literature, and there are several examples of model-based 
methods for this (Brooks, Lumsden, \& Blaxill, 2005; Burk, Jacquelin, \& Wakeman, 2003; Desantes, López, García, \& Hernández, 2002; Dimopoulos et al., 1999; Knafl, Hagena, Filipi, \& Assanis, 2005; Montgomery \& Reitz, 2000; Nozaki, Fukuma, \& Tanaka, 2005; Qiang et al., 2004; Rask \& Sellnau, 2004). A common approach is to approximate a given dynamic vehicle driving cycle as a limited number of steady-state engine operating points, and to calibrate set points in these operating points with respect to engineering targets for the complete cycle. Early work based on this approach for gasoline engine applications can be found in Rao, Cohen, Tennant, and Van Voorhies (1979), Rishavy, Hamilton, Ayers, and Keane (1977) and early work for diesel engine applications in Schmitz, Oligschläger, and Eifles (1994). An advantage with this approach is that optimal set points for steady-state engine operation can be calculated from the engine speed and the injected fuel amount only. This means that optimal set points can be calculated off-line for the complete working range of the engine with respect to engine speed and injected fuel amount, and stored in an EMS using for example grid maps. Therefore, the optimization results can be implemented as a general EMS strategy that calculates set points for any driving scenario.

During transient operation, the optimal set points are typically not directly reached due to dynamic effects in the engine air path. This, in turn, typically results in emission peaks during transient engine operation. Additional compensations are then used to keep emissions within a reasonable range. The calibration of these compensations is currently a manual process and is largely performed to meet regulations rather than to optimize the system. Research within the topic of optimizing transient engine operation has mainly been focused on finding optimal actuator trajectories for specified single engine transients. Examples of methods for this are presented in Sequenz, Mrosek, Zydek, and Isermann (2011), Alberer and del Re (2009) and Benz, Hehn, Onder, and Guzella (2011). These methods are not well suited for online implementation into a real EMS, since optimal trajectories for single transients cannot be directly transferred to an EMS strategy that can handle all possible transients in an engine.

The possibility to account for transient engine and vehicle behavior during EMS optimization becomes more important as a new global harmonized test cycle, the World-Harmonize LightDuty Test Cycle (WLTC) is being developed. The development of this new test cycle is ongoing, but the test cycle will most likely include a larger portion of transient driving compared to the currently used test cycle in Europe, the New European Driving Cycle (NEDC) (Timothy, 2012).

Some work has been performed to optimize the EMS in a diesel engine for a complete driving cycle, taking both steady-state and transient engine operation into consideration. Atkinson et al. have used a model-based approach based on neural networks to achieve a proof-of-concept of the benefit of a model-based transient calibration process (Atkinson \& Mott, 2005; Atkinson, Allain, \& Zhang, 2008). Brahma et al. have developed a modelbased transient calibration process to optimize the parametrization in a standard EMS, taking both steady-state and transient engine operation into account (Brahma \& Chi, 2011a, 2011b). The approach in their work is to complement the manual work process of performing EMS calibration, rather than to replace it. Based on an existing EMS calibration, simulation models and search algorithms are used to adjust the calibration such that emissions for a dynamic driving cycle are decreased without increasing the fuel consumption.

A novel strategy to calculate set points in a diesel EMS was introduced in Grahn, Johansson, and McKelvey (2013). The strategy is based on existing methods for steady-state EMS optimization, but extended to handle effects during transient engine operation caused by the dynamics in the engine air system. The set points are calculated on-line in the EMS by solving a number of optimization problems. The strategy was evaluated in Grahn et al. (2013) using a simple engine simulation scenario. In this paper, the strategy is further developed such that set points for the complete working range of the engine can be calculated off-line, and stored in an EMS using a structure similar to the map-based structure in a standard EMS. The developed strategy is evaluated using a complete diesel engine vehicle system simulation model driving according to three different cycles, the New European Driving Cycle (NEDC), the Federal Test Procedure (FTP-75), and the Japanese JC08 cycle.

\section{Optimization problem}

The optimization problem for an Engine Management System (EMS) can be formulated as to minimize fuel consumption for a vehicle driving according to a pre-defined driving cycle while fulfilling constraints on accumulated emissions. To fully define this optimization problem mathematically, the complete vehicle system needs to be considered, including driver, engine, EMS, and vehicle. A common method to isolate the engine from this complete optimization problem is to approximate the problem. Typically, the optimization problem is approximated such that the vehicle drive cycle is estimated as a given speed and the requested torque profile for the engine during the cycle. The simplified optimization problem is then formulated as to minimize fuel consumption for the engine while delivering the given requested torque profile. This approximation is used in e.g. Rishavy et al. (1977), Rao et al. (1979), Schmitz et al. (1994), and has also been applied in this study.

In this study, the considered EMS controllable parameters are the set point for boost pressure, $p_{\mathrm{bset}}$, the set point for the oxygen fraction in the intake manifold, $r_{\mathrm{O}_{2} \text { set }}$, and the timing of the fuel injections, $\varphi$, throughout the driving cycle. Other controllable quantities, such as injection rail pressure and injection strategy we assume are directly given by functions of engine speed and load and have been established based on prior test procedures. The considered constraints are limitations on accumulated $\mathrm{NO}_{\mathrm{X}}$ and soot emissions. The approximated optimization problem can be formulated mathematically as

$$
\begin{aligned}
& \min _{\boldsymbol{p}_{\mathbf{b s e}}, \boldsymbol{r}_{\mathbf{O}_{\text {set }}}, \boldsymbol{\varphi}} \sum_{i=1}^{N} m_{\mathrm{f}}\left(n_{\mathrm{e} i}, T_{\mathrm{e} i}, p_{\text {bact } i}, r_{\mathrm{O}_{2} \text { act } i}, \varphi_{i}\right) \\
& \text { s.t. } \sum_{i=1}^{N} f_{\mathrm{NO}_{\mathrm{x}}}\left(n_{\mathrm{e} i}, T_{\mathrm{e} i}, p_{\text {bact } i}, r_{\mathrm{O}_{2} \text { act } i}, \varphi_{i}\right) \leq \mathrm{NO}_{\mathrm{Xlim}} \\
& \sum_{i=1}^{N} f_{\text {soot }}\left(n_{\mathrm{e} i}, T_{\mathrm{e} i}, p_{\text {bact }}, r_{\mathrm{O}_{2} \text { act }}, \varphi_{i}\right) \leq \operatorname{soot}_{\text {lim }}
\end{aligned}
$$

where $N$ is the number of combustion events during the cycle, $\boldsymbol{p}_{\mathbf{b} \text { set }}$ is a vector with set points for the boost pressure $(\mathrm{Pa}), \boldsymbol{r}_{\mathbf{O}_{2 \text { set }}}$ is a vector with set points for the oxygen fraction in the intake manifold (-), and $\varphi$ is a vector with injection timings (Crank Angle Degrees (CAD)). The vectors all have $N$ elements, each corresponding to one combustion event throughout the cycle. The function $m_{\mathrm{f}}\left(n_{\mathrm{e} i}, T_{\mathrm{e} i}, p_{\mathrm{bact} i}, r_{\mathrm{O}_{2} \text { act } i}, \varphi_{i}\right)$ is the fuel amount $(\mathrm{g})$ required to deliver torque $T_{\mathrm{e} i}(\mathrm{Nm})$ at engine speed $n_{\mathrm{e} i}(\mathrm{rpm})$, boost pressure $p_{\text {bact } i}(\mathrm{~Pa})$, oxygen fraction $r_{\mathrm{O}_{2} \text { act } i}(-)$ and injection timing $\varphi_{\mathrm{i}}(\mathrm{CAD})$ corresponding to combustion event $i$. The function $f_{\mathrm{NO}_{\mathrm{x}}}\left(n_{\mathrm{e} i}, T_{\mathrm{e} i}\right.$, $p_{\mathrm{b}}$ act $\left._{i}, r_{\mathrm{O}_{2} \text { act }}, \varphi_{i}\right)$ is the amount of $\mathrm{NO}_{\mathrm{X}}$ emissions $(\mathrm{g})$, and the function $f_{\text {soot }}\left(n_{\mathrm{e} i}, T_{\mathrm{e} i}, p_{\mathrm{bacti}}, r_{\mathrm{O}_{2} \text { act }}, \varphi_{i}\right)$ is the amount of soot emissions (g) at combustion number $i$. $\mathrm{NO}_{\mathrm{Xlim}}$ is the limit on accumulated amount of $\mathrm{NO}_{\mathrm{X}}$ emissions, and soot $_{l i m}$ is the limit on accumulated soot emissions during the cycle.

It can be noted that the optimization parameters are set points for the boost pressure, $p_{\mathrm{bset}}$, and oxygen fraction, $r_{\mathrm{O}_{2} \text { set }}$, together 
with the injection timing. Feedback controllers in the EMS are used to control the Variable Geometry Turbine (VGT) and the area of the Exhaust Gas Recirculation (EGR) valve such that the boost pressure and oxygen fraction in the intake manifold reach their set points. Even though these controllers are used, the set points cannot always be reached for each combustion, due to the dynamic behavior of the gas exchange system. The resulting engine torque and emissions for each combustion event are given by the actual boost pressure, $p_{\text {bact }}$, and oxygen fraction, $r_{\mathrm{O}_{2} \text { act }}$, together with the injection timing, engine speed and injected fuel amount.

\section{Optimization algorithm}

\subsection{Steady-state approach}

A common approach to handle the optimization problem (1) is to neglect the dynamics in the engine air system, hence assume that the set points for boost pressure and oxygen fraction in the intake manifold can be directly reached at each combustion event. This leads to the following approximation of the optimization problem:

$$
\begin{aligned}
& \min _{\boldsymbol{p}_{\mathbf{b s e},}, \boldsymbol{r}_{\mathbf{O}_{2} \text { set }}, \boldsymbol{\varphi}} \sum_{i=1}^{N} m_{\mathrm{f}}\left(n_{\mathrm{e} i}, T_{\mathrm{e} i}, p_{\mathrm{bset}}, r_{\mathrm{O}_{2} \text { set }}, \varphi_{i}\right) \\
& \text { s.t. } \quad \sum_{i=1}^{N} f_{\mathrm{NO}_{\mathrm{x}}}\left(n_{\mathrm{e} i}, T_{\mathrm{e} i}, p_{\mathrm{bset} i}, r_{\mathrm{O}_{2} \mathrm{set} i}, \varphi_{i}\right) \leq \mathrm{NO}_{\mathrm{Xlim}} \\
& \sum_{i=1}^{N} f_{\text {soot }}\left(n_{\mathrm{e} i}, T_{\mathrm{e} i}, p_{\text {bset }}, r_{\mathrm{O}_{2} \text { set } i}, \varphi_{i}\right) \leq \operatorname{soot}_{\text {lim }}
\end{aligned}
$$

This optimization problem is almost identical to (1), with the only difference that the actual values for boost pressure, $p_{\text {bact }}$, and oxygen fraction, $r_{\mathrm{O}_{2} \text { act }}$, are replaced with the set points for boost pressure, $p_{\mathrm{bset}}$, and for oxygen fraction, $r_{\mathrm{O}_{2} \text { set }}$, respectively, in the functions for fuel, $\mathrm{NO}_{\mathrm{X}}$, and soot emissions. This problem (2) can be solved using a Lagrangian relaxation approach. Doing this, the solution to the optimization problem can be obtained by solving $N$ smaller problems, i.e. one optimization problem for each combustion event. The optimization problem for each combustion event is

$\min _{p_{\text {bset }}, r_{O_{\text {set }}}, \varphi}\left(m_{\mathrm{f}}+\lambda_{\mathrm{NO}_{\mathrm{x}}} f_{\mathrm{NO}_{\mathrm{x}}}+\lambda_{\text {soot }} f_{\text {soot }}\right)$

where

$$
\begin{aligned}
& m_{\mathrm{f}}=m_{\mathrm{f}}\left(n_{\mathrm{e}}, T_{\mathrm{e}}, p_{\text {bset }}, r_{\mathrm{O}_{2 \text { set }}}, \varphi\right) \\
& f_{\mathrm{NO}_{\mathrm{x}}}=f_{\mathrm{NO}_{\mathrm{x}}}\left(n_{\mathrm{e}}, T_{\mathrm{e}}, p_{\text {bset }}, r_{\mathrm{O}_{2 \text { set }}}, \varphi\right) \\
& f_{\text {soot }}=f_{\text {soot }}\left(n_{\mathrm{e}}, T_{\mathrm{e}}, p_{\text {bset }}, r_{\mathrm{O}_{2 \text { set }}}, \varphi\right)
\end{aligned}
$$

The physical interpretation of this optimization problem is that for all combustion events throughout the driving cycle, the set points for the controllable systems should be calibrated such that fuel consumption and emissions are minimized with given trade-offs, the Lagrangian multipliers, $\lambda_{\mathrm{NO}_{\mathrm{x}}}$ and $\lambda_{\text {soot }}$. The values of $\lambda_{\mathrm{NO}_{\mathrm{x}}}$ and $\lambda_{\text {soot }}$ can be chosen such that the solution to the optimization problem (2) is achieved (if the problem is feasible). Doing this, the solution to (2) encompasses optimal set points for each of the combustions in the specified driving cycle, when assuming there are no dynamics in the engine. However, by also letting (3) define set points for all remaining speed and load points in the envelope of the engine, complete maps for the set points from speed and load can be obtained. Therefore, set points for the complete working range of the engine with respect to engine speed and the requested torque can be calculated off-line by solving (3), and stored in an EMS. The resulting EMS set points are typically defined by grid maps of the following form:

$$
\begin{aligned}
& p_{\text {bset }}=M_{\mathrm{p}}\left(n_{\mathrm{e}}, m_{\mathrm{f}}\right) \\
& r_{\mathrm{O}_{2} \text { set }}=M_{\mathrm{r}_{\mathrm{O}_{2}}}\left(n_{\mathrm{e}}, m_{\mathrm{f}}\right) \\
& \varphi=M_{\varphi}\left(n_{\mathrm{e}}, m_{\mathrm{f}}\right)
\end{aligned}
$$

Doing this, the optimization approach can be implemented as a general EMS strategy that calculates set points for any driving scenario and is optimal for the selected approximated driving cycle used to define the Lagrangian multipliers.

By using this strategy, EMS settings are optimized based on steady-state engine operation only. During transient operation, emissions and fuel consumption will be different compared to the steady-state values. The main difference between steady-state and transient engine operation with respect to emissions and fuel consumption is caused by the dynamics in the air system (Glewen, Foster, \& Krieger, 2012). To account for this, additional compensations for transient engine operation are added. The calibration of these compensations is typically a manual and time consuming process, and even though these compensations are used, emissions and fuel consumption will most likely be different for the real driving cycle compared to the driving cycle approximated as steady-state engine operation. Therefore, in practice, the Lagrangian multipliers in (3) are typically chosen such that the resulting set points in the complete operating range of the engine yield a feasible solution to the original optimization problem (1). The resulting values of the Lagrangian multipliers typically differ from the values that solve (2).

A more detailed description of this procedure to optimize settings in an EMS based on steady-state engine operation can be found in e.g. Rishavy et al. (1977), and Rao et al. (1979).

\subsection{Transient extension}

The optimal solution to (2) is given by solving (3) in all engine operating points. This means that if dynamics are neglected, optimal engine operation throughout a driving cycle is achieved when all combustion events are operated with the same trade-offs between fuel consumption and emissions. The optimal solution to (1), i.e. when dynamics are considered, most likely will not fulfill the same criteria. However, it is assumed that a near-optimal solution to (1) can be found if all combustion events (both during steady-state and during transient engine operation) in a driving cycle are operated with the same trade-offs between fuel consumption and emissions. The approach to fulfill this criteria is to separate the set points based on their different corresponding time scales. The idea is that set points for faster systems should be adjusted based on actual values when slower systems have not reached their set points. As described in Section 1, there are two main causes of dynamics in the engine air system; the mechanical inertia of the turbocharger system, and the gas dynamics due to emptying and filling of volumes in the air system. Typically, the mechanical dynamics associated to the turbo system are slower, while the gas dynamics are faster. Therefore, the set point for boost pressure is assumed to be associated with the slowest dynamics, the set point for the oxygen fraction in the intake manifold with faster dynamics, and the injected timing is not associated to any dynamics.

The following strategy is applied to calculate the set points. The optimization problem (3) is solved similarly as before. But instead of using the complete solution to this optimization problem, only the set point for boost pressure, $p_{\mathrm{bset}}$, is used, since the boost pressure set point is associated with the slowest dynamics in the system. Next, a second optimization problem is solved

$\min _{r_{O_{2 \text { set }}} \varphi}\left(m_{\mathrm{f} 2}+\lambda_{\mathrm{NO}_{\mathrm{x}}} f_{\mathrm{NO}_{\mathrm{x} 2}}+\lambda_{\text {soot }} f_{\text {soot } 2}\right)$ 
where

$m_{\mathrm{f} 2}=m_{\mathrm{f}}\left(n_{\mathrm{e}}, T_{\mathrm{e}}, p_{\mathrm{bact}}, r_{\mathrm{O}_{2 \mathrm{set}}}, \varphi\right)$

$f_{\mathrm{NO}_{\mathrm{x} 2}}=f_{\mathrm{NO}_{\mathrm{x}}}\left(n_{\mathrm{e}}, T_{\mathrm{e}}, p_{\text {bact }}, r_{\mathrm{O}_{2 \mathrm{set}}}, \varphi\right)$

$f_{\text {soot } 2}=f_{\text {soot }}\left(n_{\mathrm{e}}, T_{\mathrm{e}}, p_{\text {bact }}, r_{\mathrm{O}_{2} \text { set }}, \varphi\right)$

This optimization problem is similar to (3), but with the difference that the optimization problem is solved only for the oxygen fraction set point, $r_{\mathrm{O}_{2} \text { set }}$, and the injection timing, $\varphi$. The boost pressure set point is not included in the optimization, instead the actual boost pressure in the system, $p_{\mathrm{bact}}$, is used as a given input Finally, a third optimization problem is solved

$\min _{\varphi}\left(m_{\mathrm{f} 3}+\lambda_{\mathrm{NO}_{\mathrm{x}}} f_{\mathrm{NO}_{\mathrm{x} 3}}+\lambda_{\text {soot }} f_{\text {soot } 3}\right)$

where

$m_{\mathrm{f} 3}=m_{\mathrm{f}}\left(n_{\mathrm{e}}, T_{\mathrm{e}}, p_{\mathrm{bact}}, r_{\mathrm{O}_{2} \text { act }}, \varphi\right)$

$f_{\mathrm{NO}_{\mathrm{x} 3}}=f_{\mathrm{NO}_{\mathrm{x}}}\left(n_{\mathrm{e}}, T_{\mathrm{e}}, p_{\text {bact }}, r_{\mathrm{O}_{2} \text { act }}, \varphi\right)$

$f_{\text {soot } 3}=f_{\text {soot }}\left(n_{\mathrm{e}}, T_{\mathrm{e}}, p_{\text {bact }}, r_{\mathrm{O}_{2} \text { act }}, \varphi\right)$

Again, this optimization is similar to (3) and (5), but with the difference that the optimization problem is solved only for the injection timing, $\varphi$. The boost pressure and oxygen fraction set points are not included in the optimization, instead the actual boost pressure, $p_{\text {bact }}$, and oxygen fraction, $r_{\mathrm{O}_{2} \text { act }}$, in the system are used as given inputs.

The resulting set point for the boost pressure, $p_{\mathrm{bset}}$, is given from the solution to (3), the set point for the oxygen fraction, $r_{\mathrm{O}_{2} \text { set }}$, is given from the solution to (5), and the injection timing, $\varphi$, is given from the solution to (6). The values of the Lagrangian multipliers, $\lambda_{\mathrm{NO}_{\mathrm{x}}}$ and $\lambda_{\text {soot}}$, are chosen such that the resulting set points yield a feasible solution to the original optimization problem (1).

Given the optimized values of the Lagrangian multipliers, the set point for boost pressure is a function of engine speed and requested torque, the set point for oxygen fraction is a function of engine speed, requested torque, and actual boost pressure, and the injection timing is a function of engine speed, requested torque, actual boost pressure, and actual oxygen fraction. This means that set points for the complete working range of the engine with respect to engine speed, requested torque, actual boost pressure, and actual oxygen fraction can be calculated off-line by solving (3), (5) and (6), and stored in an EMS using for example grid maps. Therefore, also this optimization approach can be implemented as a general EMS strategy that calculates set points for any driving scenario. The resulting EMS set points can be defined by grid maps of the following form:

$p_{\mathrm{bset}}=M_{\mathrm{p}}\left(n_{\mathrm{e}}, m_{\mathrm{f}}\right)$

$r_{\mathrm{O}_{2 \text { set }}}=M_{\mathrm{r}_{\mathrm{O}_{2}}}\left(n_{\mathrm{e}}, m_{\mathrm{f}}, p_{\text {bact }}\right)$

$\varphi=M_{\varphi}\left(n_{\mathrm{e}}, m_{\mathrm{f}}, p_{\mathrm{bact}}, r_{\mathrm{O}_{2} \text { act }}\right)$
The main difference between this EMS calibration approach and the calibration approach based on steady-state engine operation described in Section 3.1 is that no additional compensations for transient engine operation are needed. Set points for faster systems are automatically adjusted during transient engine operation to account for dynamic effects in slower systems.

\section{Simulation model}

To evaluate the EMS optimization strategy a diesel engine vehicle system simulation model has been used. The simulation model is described in detail in Grahn (2012), but a brief description of the model is given here. The simulation model consists of four submodels; a model for the driver, a model for the EMS, a model for the engine, and a model for the vehicle. A schematic illustration of the simulation model with its sub-models and the interfaces between them is shown in Fig. 1.

\subsection{Engine model}

As illustrated in Fig. 1, the inputs to the engine model are actuator signals from the EMS model; the area of a Variable Geometry Turbine (VGT), the opening area of an Exhaust Gas Recirculation (EGR) valve, and the fuel injection. The engine speed from the vehicle model is also an input to the engine model. The outputs from the engine model are the engine torque together with $\mathrm{NO}_{\mathrm{X}}$ and soot emissions.

The engine model is divided into two sub-models, a model for the engine air system and a model for the combustions. A schematic illustration of the two sub-models and the interfaces between them is shown in Fig. 2.

\subsubsection{Air system model}

The air system is implemented as a mean-value model based on a structure described in Wahlstrom (2009). A schematic illustration of the engine air system model with its components is shown in Fig. 3.

The components included in the model, together with short descriptions of them, are listed in Table 1.

The model catches the main fuel consumption and emission affecting dynamics in the engine air system, i.e. the turbo system dynamics, and the dynamics in the intake and exhaust manifolds.

\subsubsection{Combustion model}

Models for generated engine torque, $\mathrm{NO}_{\mathrm{x}}$, and soot emissions have been created using a data-driven model structure described in Grahn et al. (2014b). The model structure is a regression model with parameters from grid maps based on engine speed and injected fuel amount, and is designed to account for effects during transient engine operation caused by dynamics in the engine air

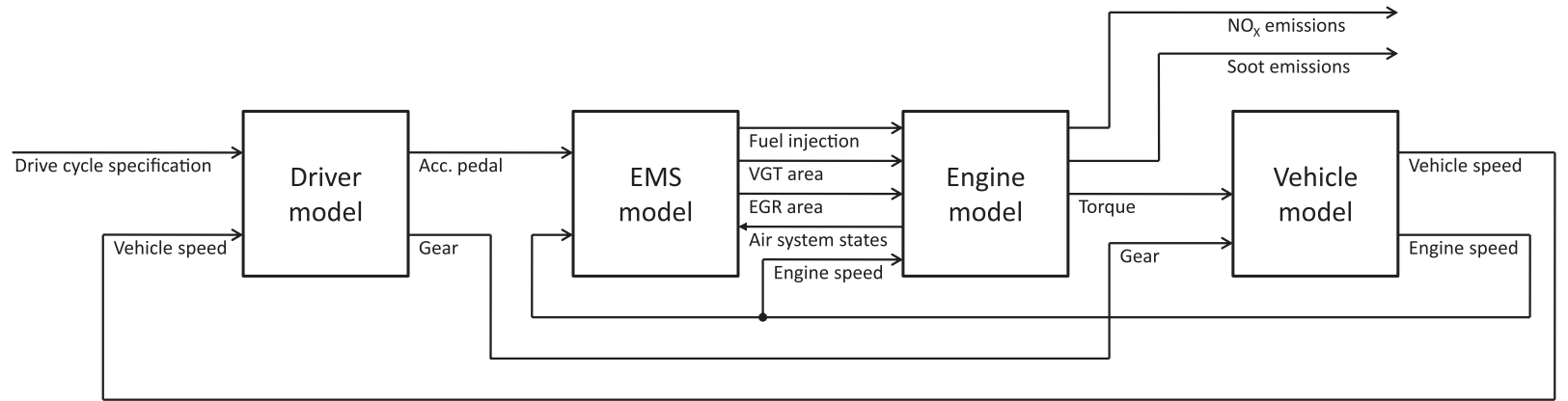

Fig. 1. Schematic illustration of the complete diesel engine vehicle system simulation model with its four sub-models and the main interfaces between them. 


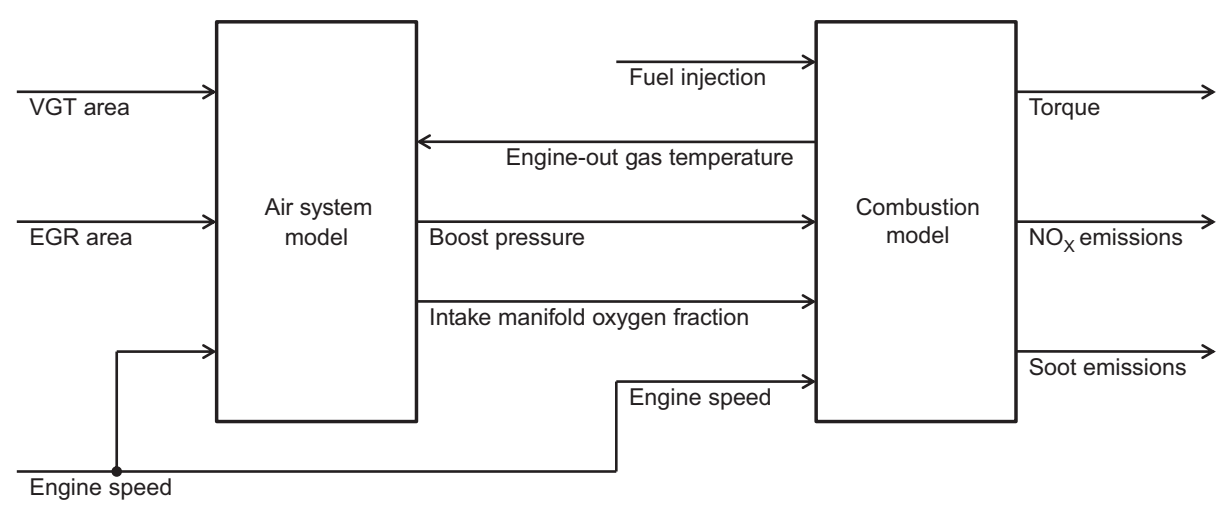

Fig. 2. Schematic illustration of the engine model with its two sub-models; the air system model and the combustion model.

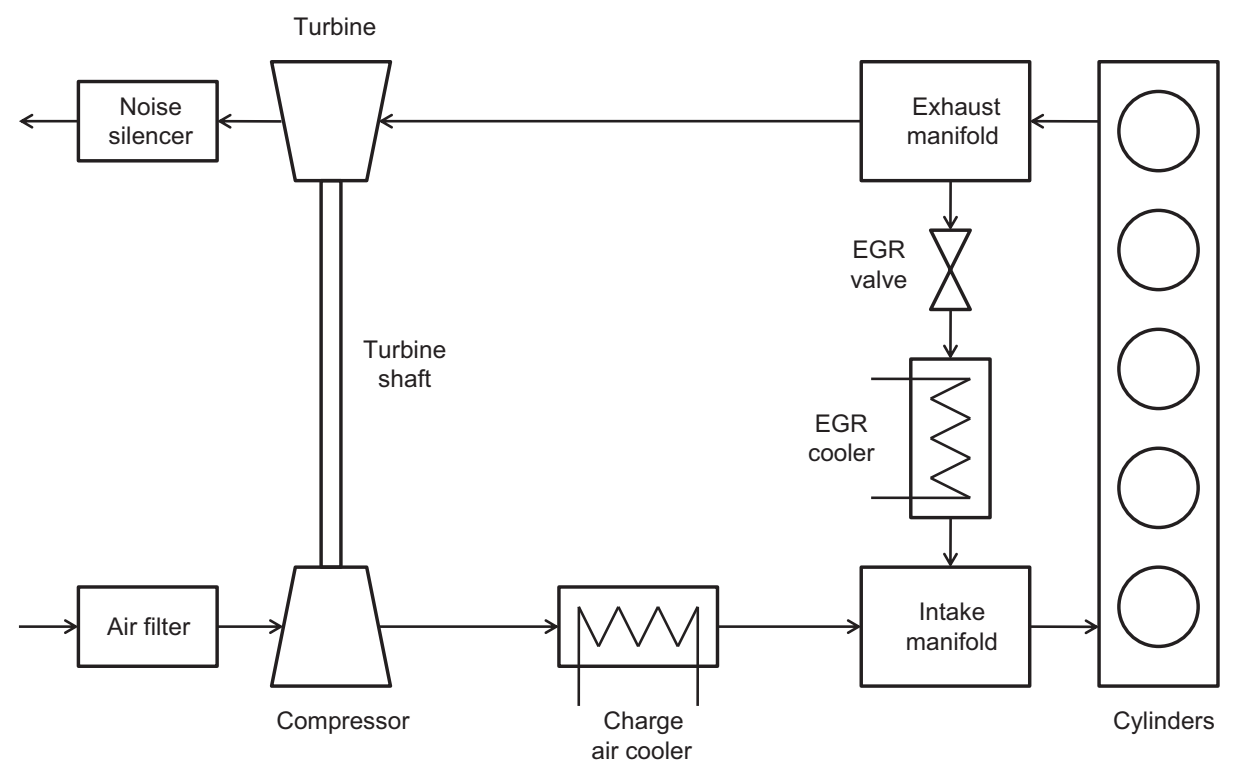

Fig. 3. Schematic illustration of the engine air system model with its sub-models.

Table 1

Air system components.

\begin{tabular}{ll}
\hline Air filter & Isothermal orifice \\
Compressor & Mass flow and efficiency \\
Charge air cooler & Isothermal orifice and cooling efficiency \\
Intake manifold & Control volume \\
Cylinders & Volumetric pump \\
Volumetric efficiency & Regression model \\
Exhaust manifold & Control volume \\
Turbine & Mass flow and efficiency \\
Noise silencer & Isothermal orifice \\
EGR valve & Isothermal orifice \\
EGR cooler & Cooling efficiency \\
Turbine shaft & Moment of inertia and Newton's second law \\
\hline
\end{tabular}

system. A model for the engine-out gas temperature has also been created using the same model structure. The engine-out gas temperature is used in the model for the engine air system. The models have all been created using steady-state engine measurement data from a Volvo 2.4 liter passenger car diesel engine. The measurements have been performed such that the operating range of the engine regarding boost pressure, oxygen fraction in the intake manifold, and injection timing has been exploited as much as possible using only steady-state engine operation. The produced engine torque, $\mathrm{NO}_{\mathrm{x}}$ emissions, soot emissions, and engine-out gas temperature are estimated as

$$
\begin{aligned}
& \hat{T}_{\mathrm{E}}=m_{\mathrm{f}} \cdot\left(f_{\mathrm{T} 0}\left(n_{\mathrm{e}}, m_{\mathrm{f}}\right)+\sum_{i=1}^{3} z_{i} \cdot f_{\mathrm{T} i}\left(n_{\mathrm{e}}, m_{\mathrm{f}}\right)\right) \\
& \hat{f}_{\mathrm{NO}_{\mathrm{x}}}=m_{\mathrm{f}} \cdot e^{\left(f_{\mathrm{N} 0}\left(n_{\mathrm{e}}, m_{\mathrm{f}}\right)+\sum_{i=1}^{3} z_{i} \cdot f_{\mathrm{Ni}}\left(n_{\mathrm{e}}, m_{\mathrm{f}}\right)\right)} \\
& \hat{f}_{\text {soot }}=m_{\mathrm{f}} \cdot e^{\left(f_{\mathrm{s} 0}\left(n_{\mathrm{e}}, m_{\mathrm{f}}\right)+\sum_{i=1}^{3} z_{i} f_{s i}\left(m_{\mathrm{f}}, n_{\mathrm{e}}\right)\right)} \\
& \hat{f}_{\mathrm{GT}}=m_{\mathrm{f}} \cdot\left(f_{\mathrm{G} 0}\left(n_{\mathrm{e}}, m_{\mathrm{f}}\right)+\sum_{i=1}^{3} z_{i} \cdot f_{\mathrm{Gi}}\left(n_{\mathrm{e}}, m_{\mathrm{f}}\right)\right)
\end{aligned}
$$

where $\hat{T}_{\mathrm{E}}$ is the estimated produced engine torque $(\mathrm{Nm}), \hat{f}_{\mathrm{NO}}$ the estimated $\mathrm{NO}_{\mathrm{x}}$ emissions $(\mathrm{g}), \hat{f}_{\text {soot }}$ the estimated soot emissions $(\mathrm{g})$, and $\hat{f}_{\mathrm{GT}}$ the estimated engine-out gas temperature $(\mathrm{K})$ at injected fuel amount $m_{\mathrm{f}}(\mathrm{g})$, engine speed $n_{\mathrm{e}}(\mathrm{rpm})$, boost pressure $z_{1}(\mathrm{~Pa})$, oxygen fraction $z_{2}(-)$, and injection timing $z_{3}$ (CAD). The functions $f_{\mathrm{T} i}, f_{\mathrm{N} i}, f_{\mathrm{si}}$, and $f_{\mathrm{G} i}, i=1 \ldots 4$ are all $8 \times 8$ grid maps with engine speed and injected fuel amount as inputs, created by fitting the models to the engine measurements. Details for these models regarding prediction performance and sensitivity to the number of chosen grid points can be found in Grahn et al. (2014b). 


\subsection{Engine Management System model}

The inputs to the Engine Management System (EMS) model are the pedal position from the driver, the engine speed from the vehicle model, and the states in the air system from the engine model. Outputs from the EMS model are the area of the variable geometry turbine (VGT), the area of the EGR valve, the injection amount, and the injection timing, see Fig. 1. The EMS model is divided into two main parts. The first part calculates the injected fuel amount together with set points for boost pressure, oxygen fraction in the intake manifold, and injection timing. The second part is controllers for the VGT and the EGR valve to achieve the calculated set points for the boost pressure and the oxygen fraction.

\subsubsection{Fuel amount and set point calculations}

The injected fuel amount is calculated linearly from the accelerator position ranging from no injected fuel mass to maximum possible injected fuel mass when the accelerator pedal position ranges from fully released (0\%) to fully depressed (100\%). The set points for boost pressure, oxygen fraction in the intake manifold, and injection timing are calculated in the EMS based on the two different EMS optimization strategies described in Section 3.

The EMS strategy based on steady-state engine operation described in Section 3.1 has been implemented using grid maps with engine speed and injected fuel amount as inputs. A schematic illustration of this EMS structure is shown in Fig. 4. Ten axis points are used in both dimensions of all grid maps, equally spaced between 750 and 2250 (rpm) for the engine speed and between 0 and 35 (mg) for the injected fuel amount. The values in the maps are calculated by solving (3) in each grid point of the maps. The models for generated torque, $\mathrm{NO}_{\mathrm{X}}$, and soot emissions described in Section 4.1.2 are used in the optimization problems. The optimization problems are solved using a grid search algorithm. Values for $p_{\mathrm{bset}}, r_{\mathrm{O}_{2} \text { set }}$, and $\varphi$ are gridded between their minimum and maximum values, and the objective function in (3) is calculated for each combination of these gridded values. The solution to (3)

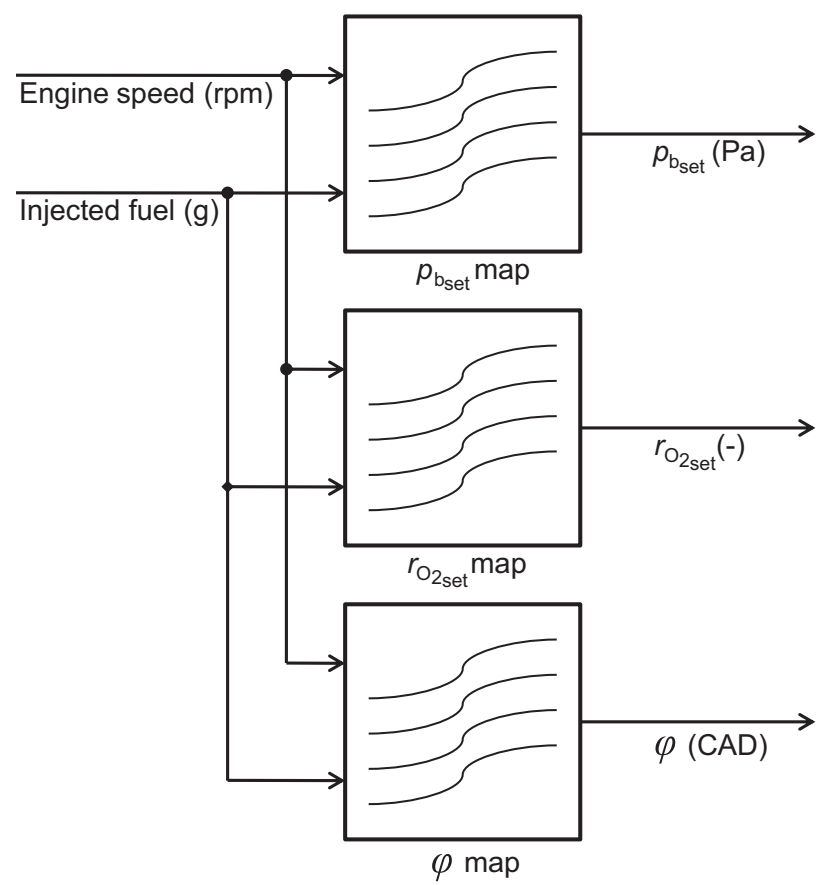

Fig. 4. Schematic illustration of the EMS structure for the optimization based only on steady-state engine operation. The structure calculates set points for boost pressure, oxygen fraction in the intake manifold, and injection timing. is given from the combination with lowest value of the objective function. Using vector notation in МАТІAB, this can be performed very effectively. The optimization problem (3) is solved in approximately $0.1 \mathrm{~s}$ on a standard computer, hence all values in the grid maps are calculated in approximately $10 \mathrm{~s}$. The values of the Lagrangian multipliers, $\lambda_{\mathrm{NO}_{\mathrm{x}}}$ and $\lambda_{\text {soot, }}$ are chosen such that the constraints for $\mathrm{NO}_{\mathrm{x}}$ and soot emissions are fulfilled when the complete simulation model is executed according to the predefined driving cycle. This is performed in an outer iterative process.

The transient extension of the EMS strategy described in Section 3.2 has also been implemented using a structure based on grid maps. The most straightforward way to implement the transient EMS strategy would be to implement the boost pressure set point as a two-dimensional grid map with engine speed and injected fuel amount as inputs, the oxygen fraction set point as a three-dimensional grid map with engine speed, injected fuel, and actual boost pressure as inputs, and finally the injection timing as a four-dimensional grid map with engine speed, injected fuel, actual boost pressure, and actual oxygen fraction as inputs. However, to decrease the required ranges of the maps, a slightly modified EMS structure has been implemented. Instead of using actual boost pressure and actual oxygen fraction directly as inputs to the maps, deviations from base set points are used, i.e. the differences between the set points calculated in (3) and the actual values in the engine. Also, instead of storing the resulting set points in the maps, the differences between the resulting set points and the set points calculated in (3) are stored in the maps. In this study, the values of the actual boost pressure and actual oxygen fraction in the intake manifold are taken from the air system model. In a real vehicle, the actual boost pressure is typically available in the EMS via a pressure sensor in the intake manifold, and the actual oxygen fraction in the intake manifold is typically estimated using a virtual sensor (Robert Bosch GmbH, 2003). A schematic illustration of the implemented transient EMS structure is shown in Fig. 5.

It can be noted, that this EMS structure can be interpreted as a steady-state EMS structure combined with a structure for transient compensation, similar to the structure in a common EMS (Robert Bosch $\mathrm{GmbH}, 2003$ ). Ten axis points are used in all dimensions of all maps. The injected fuel amount is equally spaced between 0 and 35 (mg), the engine speed is equally spaced between 750 and 2250 (rpm), the boost pressure deviation is equally spaced between $-10^{5}$ and $10^{5}(\mathrm{~Pa})$, and the oxygen fraction deviation is equally spaced between -0.1 and $0.1(-)$. The values in the maps for boost pressure set points, oxygen fraction base set points, and injection timing base are calculated by solving (3) in all grid points in the maps. The values in the oxygen fraction compensation grid map are calculated by solving (5) in each grid point, and finally the values in the injection timing compensation map are calculated by solving (6) in each grid point. Again, the models for generated torque, $\mathrm{NO}_{\mathrm{X}}$, and soot emissions described in Section 4.1.2 are used to solve the optimization problems. Similar to the steady-state approach, the optimization problems are all solved using a grid search algorithm. To calculate all values in all grid maps a total number of 11,100 optimization problems need to be solved. This is performed in approximately $15 \mathrm{~min}$ on a standard computer. The values of the Lagrangian multipliers, $\lambda_{\mathrm{NO}_{x}}$ and $\lambda_{\text {soot, }}$ are also here chosen such that the constraints for $\mathrm{NO}_{\mathrm{X}}$ and soot emissions are fulfilled when executing the complete vehicle system simulation model according to the specified driving cycle.

\subsubsection{Air system controllers}

The calculated fuel injection amount and injection timing can be directly controlled by the EMS, and are used as outputs from 


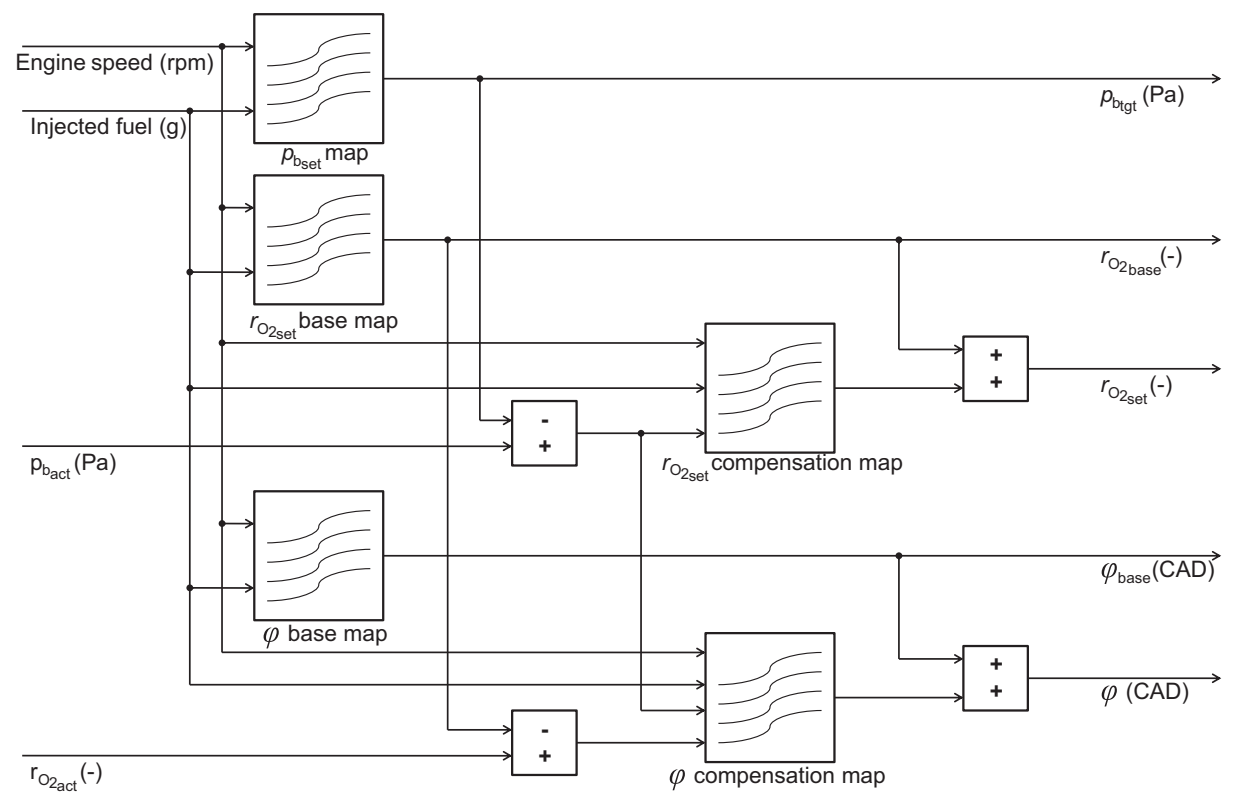

Fig. 5. Schematic illustration of the EMS structure for the transient extension of the optimization. The structure calculates set points for boost pressure, oxygen fraction in the intake manifold, and injection timing.

the EMS model. The set points for boost pressure and oxygen fraction in the intake manifold are used as inputs to the controller part of the EMS model. The task of the controller part of the EMS model is to set the area of the VGT and the area of the EGR valve to reach the set points for boost pressure and oxygen fraction in the intake manifold. The system that the controllers should act on is also a sub-model in the complete simulation model, i.e. the air system model described in Section 4.1.1. Therefore, model-based controllers have been implemented for the VGT and the area of the EGR valve. Details regarding the implemented controllers can be found in Grahn (2012).

\subsection{Driver model}

The driver actuates the accelerator pedal to drive the vehicle according to the predefined driving cycle. The input signal to the driver model is the vehicle speed, and the output signals are the accelerator pedal position and the gear (Fig. 1). An input to the driver model is also a vehicle driving cycle, which is defined as a target vehicle speed and gear along the time axis.

The gear output from the driver model is given directly from the vehicle driving cycle, and the accelerator pedal position is calculated using a standard PI controller. The difference between the target vehicle speed and the actual vehicle speed (from the vehicle model) is used as an input to the controller, and the accelerator pedal position is the output. The coefficients for the PI controller were manually set such that the vehicle speed tolerances specified in EU (1970) were fulfilled.

\subsection{Vehicle model}

As shown in Fig. 1, the inputs to the vehicle model are the torque from the engine model and the gear from the driver model, and the outputs are the vehicle speed and the engine speed. The model for the vehicle has two different modes, depending on if a gear is engaged or not. When a gear is engaged, the engine speed and the vehicle speed is connected via a ratio depending on the gear. When no gear is engaged, the engine and the vehicle are modeled as two separate systems. The vehicle, the engine, and the combined system are all modeled using Newtons second law, i.e. the acceleration of the system is calculated from the total force on the system and the mass of the system. The forces and torques that are included in the model are the driving torque from the engine, the friction torque on the engine, the rolling resistance of the vehicle, and the aerodynamic drag force on the vehicle. The driving torque from the engine is an input from the engine model. Models for the rolling resistance of the vehicle, the aerodynamic drag force on the vehicle, and the friction torque on the engine are estimated according to models described in Heywood (1988). A detailed description of the implemented vehicle model can be found in Grahn (2012).

\section{Results}

Studies were performed to evaluate the proposed transient EMS optimization strategy, and to compare it with the strategy based only on steady-state engine operation. The simulation model of the engine has been created using measurements from an engine designed for Euro $\mathrm{V}$ emission standards. Therefore, the constraints on accumulated $\mathrm{NO}_{\mathrm{X}}$ and soot emissions were set to fulfill Euro V requirements for The New European Driving Cycle (NEDC). This corresponds to a limit on accumulated amount of $\mathrm{NO}_{\mathrm{X}}$ emissions of $1.98 \mathrm{~g}$, and accumulated amount of soot emissions of $55 \mathrm{mg}$ for the total duration of the cycle. The steady-state EMS optimization strategy and the proposed transient extension strategy were both evaluated. For each strategy, the values of the Lagrangian multipliers were chosen such that the emission constraints were fulfilled for the NEDC driving cycle. Given the resulting settings optimized for the NEDC driving cycle, the performance of the two strategies were also evaluated using two other driving cycles, the Federal Test Procedure (FTP-75), and the Japanese JC08 test cycle. The three studied driving cycles, NEDC, FTP-75, and JC08, are illustrated in Fig. 6.

\subsection{NEDC driving cycle}

Resulting fuel consumption for the NEDC driving cycle was $428.1 \mathrm{~g}$ for the strategy based on steady-state engine operation and $425.7 \mathrm{~g}$ for the transient extension strategy. This corresponds 


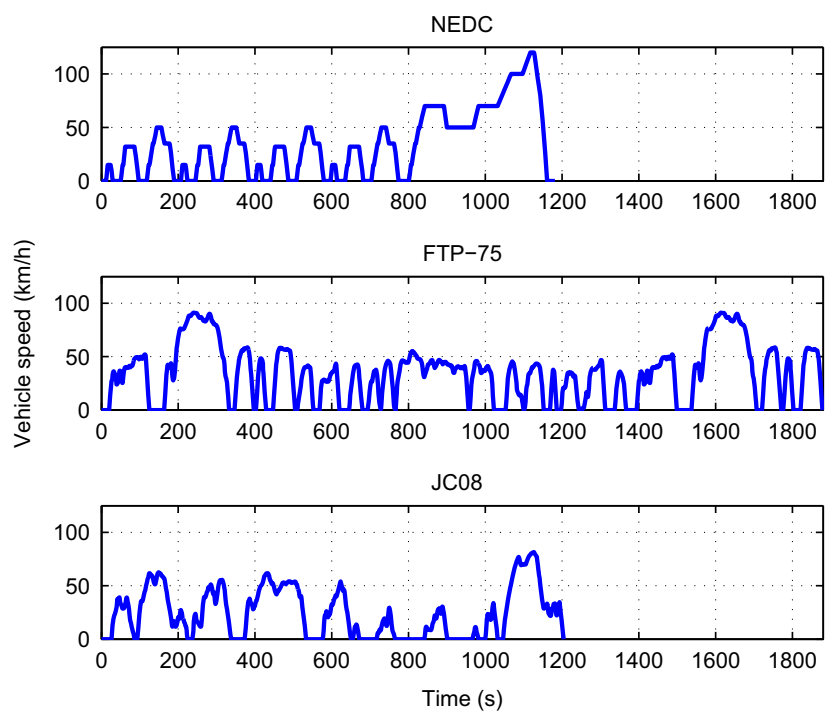

Fig. 6. Illustration of the three studied driving cycles. The figure shows the desired vehicle speeds for the New European Driving Cycle (upper), the Federal Test Procedure (middle), and the Japanese JC08 cycle (lower).
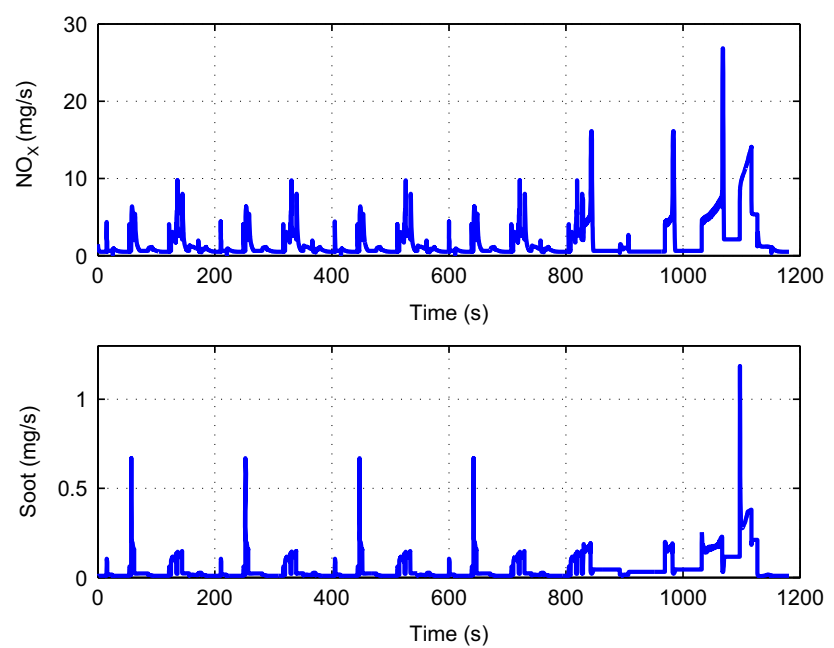

Fig. 7. $\mathrm{NO}_{\mathrm{X}}$ and soot emissions during the NEDC driving cycle when the EMS strategy based on steady-state engine operation is used.

to a decrease in fuel consumption of $0.56 \%$. The accumulated $\mathrm{NO}_{\mathrm{X}}$ emissions were $1.98 \mathrm{~g}$, and the accumulated soot emissions were $55 \mathrm{mg}$ for both strategies (the values of the Lagrangian multipliers were chosen to accomplish this).

The resulting $\mathrm{NO}_{x}$ and soot emissions during the NEDC driving cycle for the two different strategies are illustrated in Figs. 7 and 8. As seen in the figures, the emissions during the cycle are different for the two different EMS strategies. The main difference is that the emission peaks during transient engine operation are typically lower for the transient EMS strategy. To highlight the resulting difference between the two strategies, the differences between accumulated $\mathrm{NO}_{\mathrm{X}}$ emissions, soot emissions, and fuel consumption throughout the driving cycle are illustrated in Fig. 9. As seen in the figure, there are differences in the emissions throughout the driving cycle, but the differences even out for the complete cycle. There are also differences between the fuel consumptions throughout the cycle, and the accumulated difference for the complete NEDC driving cycle is $2.4 \mathrm{~g}$.
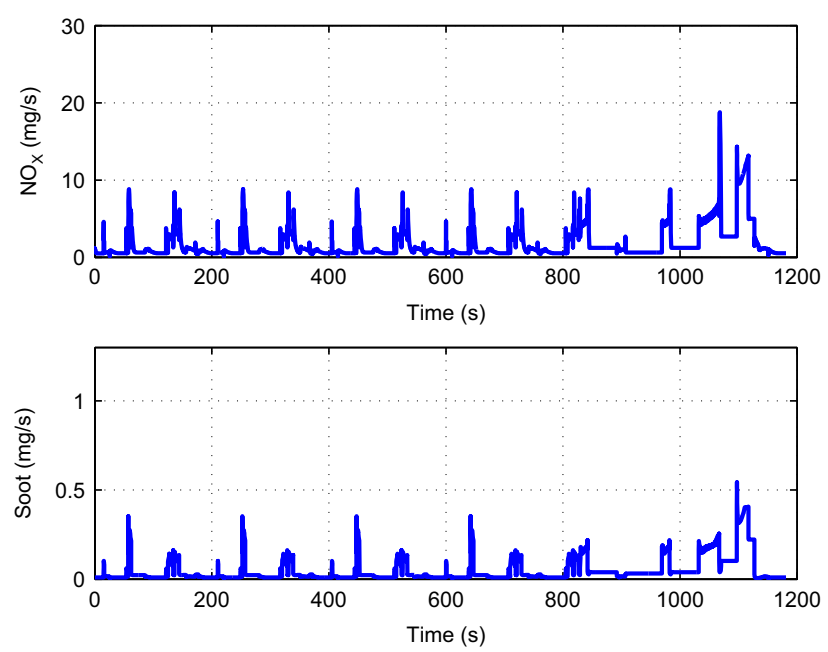

Fig. 8. $\mathrm{NO}_{\mathrm{X}}$ and soot emissions during the NEDC driving cycle when the transient EMS strategy described in this paper is used.
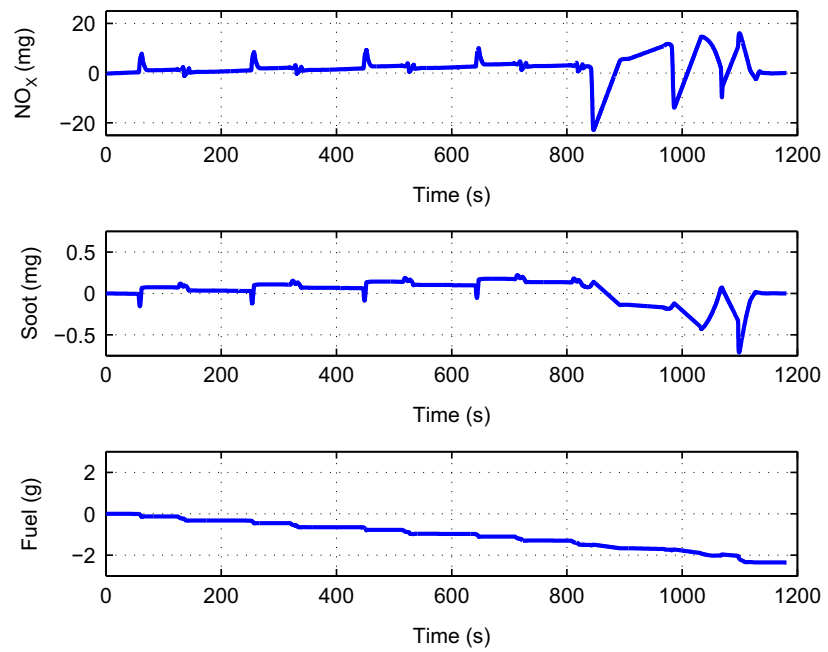

Fig. 9. Difference between accumulated $\mathrm{NO}_{\mathrm{x}}$ emissions, soot emissions, and fuel consumption throughout the NEDC driving cycle when using the transient EMS optimization strategy compared to when using an EMS optimization strategy based only on steady-state engine operation.

To further illustrate the resulting difference between the two different EMS strategies, the EMS set points during a small part of the simulations are shown for the two different EMS strategies. For the steady-state EMS strategy, the set points for boost pressure, oxygen fraction, and injection timing, together with the actual values of these quantities are illustrated in Fig. 10.

As seen in the figure, the boost pressure and the oxygen fraction do not directly reach their set points during the transient. The $\mathrm{NO}_{\mathrm{X}}$ and soot emissions, and fuel consumption during the same time period are illustrated in Fig. 11.

The emissions during the period when the set points are not reached are high, especially there is a big peak of soot emissions during the time when neither the boost pressure nor the oxygen fraction has reached their set points.

For the transient extension, the EMS set points during the same time period are illustrated in Fig. 12. To emphasize the effect of the transient extension, also the base values, i.e. the values before the compensations (see Fig. 5) are shown in the figure.

The boost pressure set point, and therefore also the actual boost pressure, show very similar behavior compared to the steady-state 

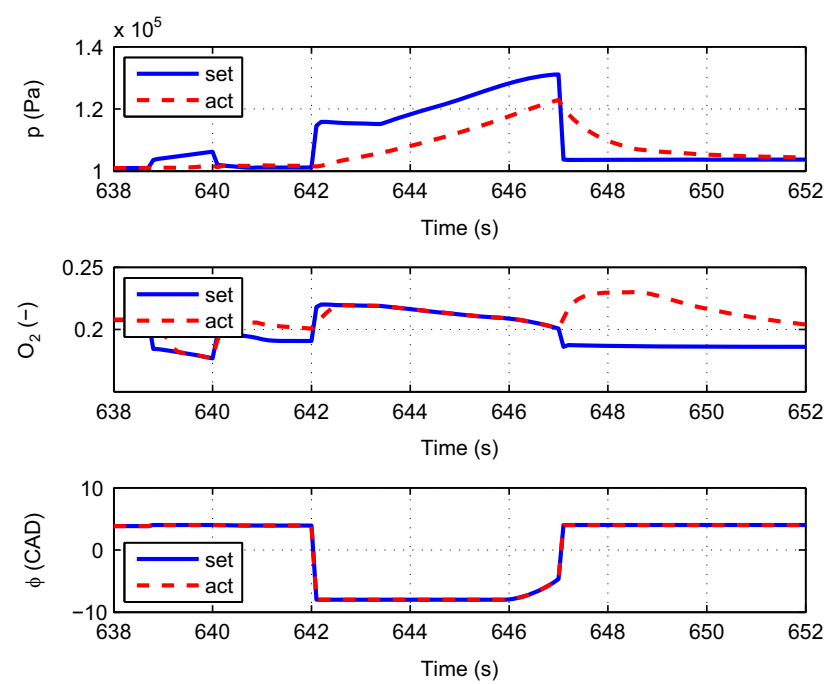

Fig. 10. EMS set points and actual values for the controllable quantities during a part of the complete NEDC driving cycle when the EMS strategy based on steadystate engine operation is used. The upper graph shows boost pressure set points (blue) together with actual boost pressure (red), the middle graph shows oxygen fraction set points (blue) together with actual oxygen fraction (red), and the lower graph shows the injection timing set points (blue) together with the actual values (red). There are no dynamics associated with the injection timing, hence the actual values are equal to the set points. (For interpretation of the references to color in this figure caption, the reader is referred to the web version of this paper.)
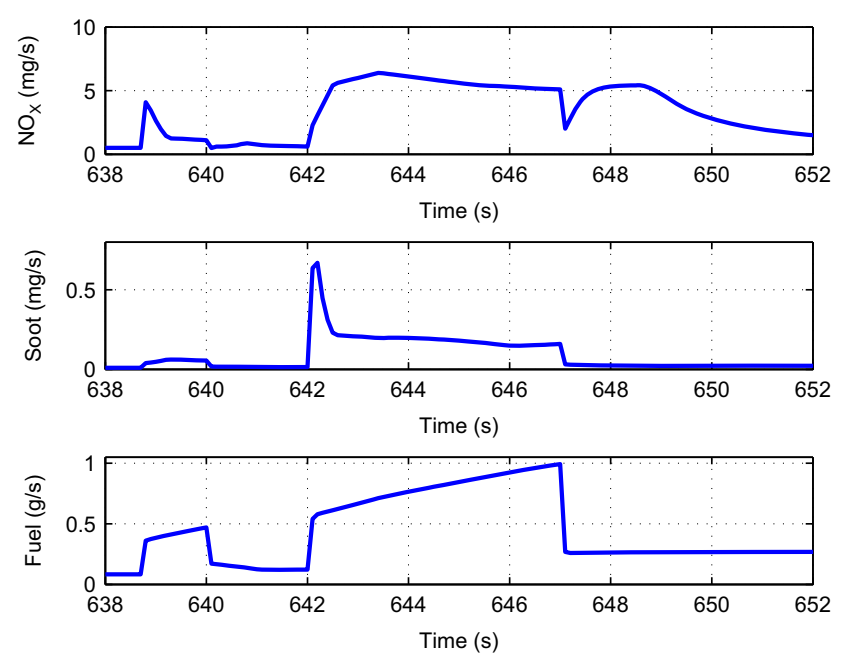

Fig. 11. $\mathrm{NO}_{\mathrm{x}}$ and soot emissions together with the fuel consumption during part of the NEDC driving cycle when the EMS strategy based on steady-state engine operation is used.

approach. This is expected, since the boost pressure set point is calculated based solely on the engine speed and injected fuel amount for both strategies. However, for the transient strategy, it can be seen that the oxygen fraction set point is adjusted when there is a deviation between the boost pressure set point and the actual boost pressure. Similar behavior is shown for the injection timing. The injection timing is adjusted when there are boost pressure or oxygen fraction deviations. The fuel consumption together with the $\mathrm{NO}_{\mathrm{X}}$ and soot emissions for the transient strategy during the same time period are illustrated in Fig. 13.

Comparing with Fig. 11, it can be noted that the soot emissions during transient engine operation are significantly lower when using the transient EMS strategy, while the $\mathrm{NO}_{\mathrm{x}}$ emissions actually are higher. It might seem strange that the $\mathrm{NO}_{\mathrm{X}}$ emissions are higher during a transient when a strategy to handle transient
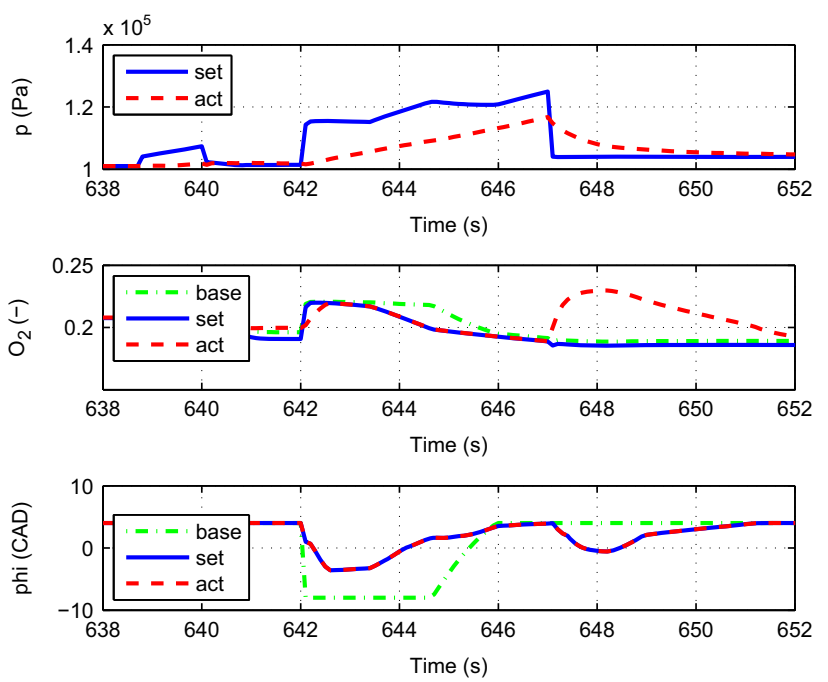

Fig. 12. EMS set points and actual values of the controllable quantities during a part of the complete NEDC driving cycle when the transient EMS strategy is used. The upper graph shows boost pressure set points (blue) together with actual boost pressure (red). The middle graph shows the base set points for the oxygen fraction (green), the final set points for the oxygen fraction (blue), and the actual oxygen fraction (red). The lower graph shows the base value for the injection timing (green), the final set points for the injection timing (blue), and the actual injection timing (red). There are no dynamics associated with the injection timing, hence the actual values are equal to the set points. (For interpretation of the references to color in this figure caption, the reader is referred to the web version of this paper.)
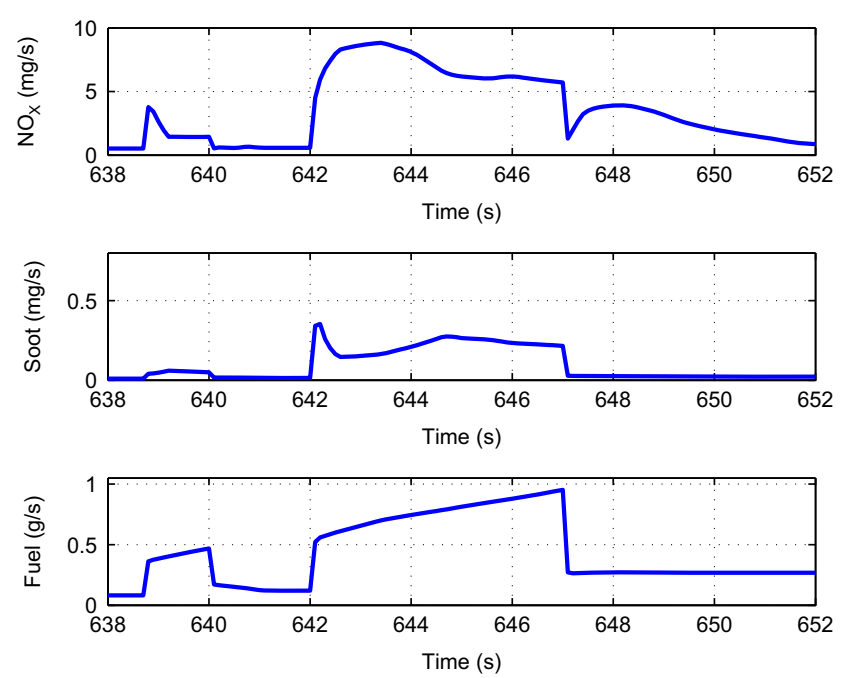

Fig. 13. $\mathrm{NO}_{\mathrm{x}}$ and soot emissions, together with the fuel consumption during part of the NEDC driving cycle when the transient EMS strategy described in this paper is used.

engine operation is used. However, the optimization strategy takes the complete driving cycle into consideration, and in this case it is beneficial to allow more $\mathrm{NO}_{\mathrm{X}}$ emissions during the transient in favor for lower fuel consumption and soot emissions. $\mathrm{NO}_{\mathrm{X}}$ emissions are instead lower during other parts of the cycle, where it causes less penalty on fuel consumption and soot emissions. This example highlights the importance of simultaneous calibration of both steady-state and transient engine operation.

When comparing the two different strategies, it can also be noted that the optimized EMS set points, and therefore also the fuel consumption and emissions, are different not only during transient engine operation, but also during steady-state engine operation. This is expected, since the different strategies are 
optimized with respect to the same given limits on accumulated emissions. The set points from the two different strategies, and therefore the emissions, are different during transient engine operation. The values of the Lagrangian multipliers, $\lambda_{\mathrm{NO}_{\mathrm{x}}}$ and $\lambda_{\text {soot}}$, are chosen for the different strategies such that the given limits on accumulated emissions are fulfilled, hence the resulting values of the multipliers become different for the two different EMS strategies. This, in turn, results in differences in the EMS set points also during steady-state engine operation.

\subsection{FTP-75 and JC08 driving cycles}

Using the Lagrangian multipliers optimized for the NEDC driving cycle, simulations were performed using two other driving cycles, the Federal Test Procedure (FTP-75) and the Japanese JC08 test cycle. For the FTP-75 cycle, the EMS approach based on steady-state engine operation resulted in a fuel consumption of $731.4 \mathrm{~g}, \mathrm{NO}_{\mathrm{x}}$ emissions of $4.51 \mathrm{~g}$, and soot emissions of $103 \mathrm{mg}$, while the transient EMS approach resulted in a fuel consumption of $723.8 \mathrm{~g}$, $\mathrm{NO}_{\mathrm{X}}$ emissions of $4.35 \mathrm{~g}$, and soot emissions of $94 \mathrm{mg}$. This corresponds to a decrease in fuel consumption of $1.04 \%$, a decrease in $\mathrm{NO}_{\mathrm{X}}$ emissions of $3.6 \%$, and a decrease in soot emissions of $8.7 \%$ when using the transient EMS approach. For the JC08 cycle, the EMS approach based on steady-state engine operation resulted in a fuel consumption of $321.6 \mathrm{~g}, \mathrm{NO}_{\mathrm{x}}$ emissions of $2.24 \mathrm{~g}$, and soot emissions of $54 \mathrm{mg}$, while the transient EMS approach resulted in a fuel consumption of $318.9 \mathrm{~g}$, $\mathrm{NO}_{\mathrm{x}}$ emissions of $2.05 \mathrm{~g}$, and soot emissions of $53 \mathrm{mg}$. This corresponds to a decrease in fuel consumption of $0.84 \%$, a decrease in $\mathrm{NO}_{\mathrm{X}}$ emissions of $8.5 \%$, and a decrease in soot emissions of $1.9 \%$. For both the FTP-75 cycle and the JC08 cycle, the fuel consumption decrease is larger than the decrease for the NEDC driving cycle, and for both cycles, both $\mathrm{NO}_{\mathrm{X}}$ and soot emissions also decrease. The reason for this is that both these cycles include a larger portion of transient driving compared to the NEDC driving cycle, increasing the benefit of the proposed transient EMS strategy. For both the FTP-75 and the JC08 cycles, the fuel consumption decrease potential is even larger if the Lagrangian multipliers are re-optimized for these cycles. For both cycles, the transient EMS strategy was re-optimized towards the emission levels resulting from the steady-state EMS strategy. Doing this, resulting fuel consumption for the FTP-75 cycle was $723.1 \mathrm{~g}$ and resulting fuel consumption for the JC08 cycle was $318.2 \mathrm{~g}$. This corresponds to a fuel consumption decrease of $1.13 \%$ for the FTP-75 cycle and $1.06 \%$ for the JC08 cycle compared to the steady-state EMS strategy. The results from these simulations are summarized in Table 2.

\section{Table 2}

Comparison between the EMS approach based on steady-state engine operation and the transient EMS approach for three different driving cycles. Fuel consumption, $\mathrm{NO}_{\mathrm{x}}$ emissions, and soot emissions for the two approaches are shown for the NEDC, FTP-75, and JC08 driving cycles. Results for the transient EMS approach are shown when it is optimized towards the NEDC driving cycle, and also when it is optimized towards the separate cycles respectively.

\begin{tabular}{|c|c|c|c|c|c|c|}
\hline Cycle & Result & $\begin{array}{l}\text { Steady- } \\
\text { state }\end{array}$ & $\begin{array}{l}\text { Transient } \\
\text { (NEDC opt) }\end{array}$ & $\begin{array}{l}\text { Difference } \\
\text { (NEDC opt) }\end{array}$ & $\begin{array}{l}\text { Transient } \\
\text { (re-opt) }\end{array}$ & $\begin{array}{l}\text { Difference } \\
\text { (re-opt) }\end{array}$ \\
\hline \multirow[t]{3}{*}{ NEDC } & Fuel (g) & 428.1 & 425.7 & $-0.56 \%$ & - & - \\
\hline & $\mathrm{NO}_{\mathrm{X}}(\mathrm{g})$ & 1.98 & 1.98 & $0 \%$ & - & - \\
\hline & Soot (mg) & 55 & 55 & $0 \%$ & - & - \\
\hline \multirow[t]{3}{*}{ FTP-75 } & Fuel (g) & 731.4 & 723.8 & $-1.04 \%$ & 723.1 & $-1.13 \%$ \\
\hline & $\mathrm{NO}_{\mathrm{X}}(\mathrm{g})$ & 4.51 & 4.35 & $-3.6 \%$ & 4.51 & $0 \%$ \\
\hline & Soot (mg) & 103 & 94 & $-8.7 \%$ & 103 & $0 \%$ \\
\hline \multirow[t]{3}{*}{ JC08 } & Fuel (g) & 321.6 & 318.9 & $-0.84 \%$ & 318.2 & $-1.06 \%$ \\
\hline & $\mathrm{NO}_{\mathrm{X}}(\mathrm{g})$ & 2.24 & 2.05 & $-8.5 \%$ & 2.24 & $0 \%$ \\
\hline & Soot (mg) & 54 & 53 & $-1.9 \%$ & 54 & $0 \%$ \\
\hline
\end{tabular}

\section{Discussion}

The described transient EMS strategy has been shown to be able to decrease fuel consumption for a given dynamic vehicle driving cycle with given limits on accumulated emissions, compared to a strategy that is based only on steady-state engine operation. The resulting fuel consumption decrease of $0.56 \%$ for the NEDC driving cycle, $1.04 \%$ (or $1.13 \%$ ) for the FTP-75 cycle, and $0.84 \%$ (or $1.06 \%$ ) for the JC08 cycle in this study can be compared with the initial evaluation of the proposed EMS strategy described in Grahn et al. (2013), where a fuel consumption decrease between 0 and $0.7 \%$ was achieved for a simple transient engine simulation scenario, depending on the given limits on accumulated emissions. The results in this study are within a similar range.

The fuel consumption decrease potential is dependent on several factors. In this study it is shown that the decrease potential is dependent on the studied driving cycle, and in Grahn et al. (2013) it is shown that the decrease potential is dependent on the given emission limits. Furthermore, the potential is most likely dependent on the characteristics of the engine, the properties of the vehicle, etc. Future work will be devoted to study the influence of these different factors on the fuel consumption decrease potential.

Assuming that the prediction accuracy of the complete simulation model is very good, the optimization of the set points could be performed off-line as in this study, and then implemented and validated in a real vehicle driving according to the specified driving cycle. However, prediction errors in the model lead to deviations between the predicted and the measured result. Therefore, in practice, it is likely that the process needs to be iterated using a real vehicle until final results are satisfactory. The better the model performance is, the fewer iterations will have to be performed. This iteration procedure is already used today when the optimization method based on steady-state engine operation is used.

For given values of the Lagrangian multipliers, the values in the grid maps for the steady-state approach are calculated in approximately $10 \mathrm{~s}$, while the values in the grid maps for the transient approach are calculated in approximately $15 \mathrm{~min}$. At this stage, no specific effort has been put in to optimize the calculations with respect to calculation time, and the calculation times can most likely be shortened. However, when used in practice, the most time consuming process is to iterate the calculations with evaluation of the performance on a real vehicle. In this context, the time to calculate the values in the grid maps is not a critical issue.

The prediction performance of the different sub-models influences different part of the optimization. The optimality of the final solution is only influenced by the accuracy of the combustion models, i.e. the models for generated engine torque, $\mathrm{NO}_{\mathrm{x}}$, and soot emissions. All other sub-models, i.e. the engine air system, the driver, the EMS, and the vehicle are only used to find the optimal values of the Lagrangian multipliers. Therefore, the prediction performance of these systems will only influence the number of iterations that has to be performed using a real vehicle.

In this study the models that are used for optimization are the same as the models used for evaluation. If this strategy should be implemented on a real engine, this would not be the case. Models for the engine would be used to calculate the EMS set points, but the final emissions and produced engine work will be generated by the real engine. However, the same models are used both for the introduced transient strategy and the strategy based on steady-state engine operation only, hence the comparison between the different strategies should be valid.

The data-driven models for the combustions have been created using measured engine data. To limit the number of measurements, the engine has been operated at 2596 different operating 
points, found according to D-optimal design methodology (Montgomery, 2009). The collected data has been fitted to models describing engine torque, $\mathrm{NO}_{\mathrm{x}}$ and soot emissions. In order to obtain more informative data for the limited amount of measurements, engine operation at high speed and torque was not considered, but the focus was kept on the region where the studied driving cycles reside. The performed measurements covered only part of the available speed and torque range of a Volvo 2.4 liter passenger car diesel engine. This, however, does not infringe the generality of the proposed method. Utilization of the entire available speed and torque range will be considered in future studies when EMS set points are to be calculated for the complete working range of the engine.

The resulting EMS set points from the optimization based on steady-state engine operation can be calculated using only the engine speed and injected fuel amount. Therefore, set points for the complete working range of the engine can be calculated offline and stored in a real EMS using two-dimensional grid maps. The calculation of the set points using the transient extension is more complex, and two-, three-, and four-dimensional grid maps are needed for online implementation for boost pressure set points, oxygen fraction set points, and injection timing respectively. In a recent study presented in Grahn, Johansson, and McKelvey (2014a), it is demonstrated that the strategy can be modified such that it can be implemented using only twodimensional grid maps, without significantly decreasing the performance.

In this study, only three of the controllable EMS quantities have been considered, i.e. boost pressure, oxygen fraction in the intake manifold, and injection timing. In a modern passenger car diesel engine there are several more degrees of freedom (Robert Bosch $\mathrm{GmbH}, 2003$ ). For example, the fuel injection can be separated in several different injection pulses, each with controllable timings and amounts. Since there are no dynamics associated to these properties, the possibility to account for them in the optimization strategy is straightforward. The only difference is that the combustion models need to account for changes in these parameters, and that there will be more optimization variables in the local optimization problems.

Engine warm-up is not considered in this study, although the optimization strategy could be adapted to handle also this. One solution for this would be to add the coolant temperature as one more engine state, with even slower dynamics than the boost pressure, and extend the described strategy to four steps instead of three. This method requires that there are simulation models available that account for the coolant temperature regarding produced torque and generated emissions. An alternative would be to simply use the same procedure as now, but choose values of the Lagrangian multipliers such that the resulting solution is feasible for a real vehicle during engine warm-up. Another alternative would be to use a strategy described in Altenstrasser et al. (2012), where separate compensations on the set points, based on the coolant temperature, have been implemented.

\section{Summary}

A strategy to calculate set points for EMS controllable quantities has been described, further developed, and evaluated. The set points are calculated with an aim to minimize fuel consumption for a dynamic driving cycle, while keeping accumulated $\mathrm{NO}_{\mathrm{X}}$ and soot emissions below given limits. The strategy is developed to account for dynamics in the engine air system, hence it calculates set points for steady-state engine operation, but also automatically introduces compensations for transient engine operation. Optimal set points for the complete working range off the engine can be calculated off-line and stored in an EMS. Therefore, the optimization results can be implemented as a general EMS strategy that calculates set points for any driving scenario.

The strategy has been evaluated using a complete diesel engine vehicle simulation model driving according to three different cycles. The introduced strategy has been shown to be able to decrease fuel consumption for all studied cycles, compared to a strategy that does not account for dynamics in the engine air system. For the simulation model used in this study, fuel consumption was decreased with $0.56 \%$ for the NEDC driving cycle, $1.04 \%$ for the FTP-75 driving cycle, and $0.84 \%$ for the JC08 cycle.

\section{References}

Alberer, Daniel \& del Re, Luigi. (2009). Optimization of the transient Diesel engine operation. SAE Technical Paper 2009-24-0113.

Altenstrasser, Harald, Kato, Yoshihisa, Keuth, Nikolaus \& Winsel, Thomas. (2012). MiL-Based Calibration and Validation of Diesel-ECU Models Using Emission and Fuel Consumption Prediction during Dynamic Warm-Up Tests (NEDC). SAE Technical Paper 2012-01-0432.

Atkinson, Chris, Allain, Marc \& Zhang, Houshun. 2008. Using Model-Based Rapid Transient Calibration to Reduce Fuel Consumption and Emissions in Diesel Engines. SAE Technical Paper 2008-01-1365.

Atkinson, Chris \& Mott, Gregory. (2005). Dynamic Model-Based Calibration Optimization: An Introduction and Application to Diesel Engines. SAE Technical Paper 2005-01-0026.

Benz, Michael, Hehn, Markus, Onder, Christopher H., \& Guzella, Lino (2011). ModelBased Actuator Trajectories Optimization for a Diesel Engine Using a Direct Method. Journal of Engineering for Gas Turbines and Power, 133(023806-1), http://dx.doi.org/10.1115/1.4001807.

Brahma, Indranil, \& Chi, John N. (2011a). Development of a model-based transient calibration process for diesel engine electronic control module tables - Part 1: data requirements, processing, and analysis. International Journal of Engine Research, 13, 77-96.

Brahma, Indranil, \& Chi, John N. (2011b). Development of a model-based transient calibration process for diesel engine electronic control module tables - Part 2: modelling and optimization. International Journal of Engine Research, 13, 147-168.

Brooks, T., Lumsden, G. \& Blaxill, H. (2005). Improving Base Engine Calibrations for Diesel Vehicles through the Use of DoE and Optimization Techniques. SAE Technical Paper 2005-01-3833.

Burk, Reinhard, Jacquelin, Frederic \& Wakeman, Russell. (2003). A Contribution to Predictive Engine Calibration Based on Vehicle Drive Cycle Performance. SAE Technical Paper 2003-01-0225.

Desantes, Jos'e M., L'opez, Jos’e J., Garc'ia, Jos’e M. \& Hern`andez, Leonor. (2002). Application of Neural Networks for Prediction and Optimization of Exhaust Emissions in a H.D. Diesel Engine. SAE Technical Paper 2002-01-1144.

Dimopoulos, P., Schni, A., Eggimann, A., Sparti, C., Vaccarino, E. \& Operti, C.. (1999). Statistical Methods for Solving the Fuel Consumption/Emission Conflict on DIDiesel Engines. SAE Technical Paper 1999-01-1077.

EU. (March 1970). Directive 70/220/EEC of the European Parliament and of the Council on the approximation of the laws of the Member States relating to measures to be taken against air pollution by gases from positive-ignition engines of motor vehicles. Official Journal of the European Communities, $L, 76 / 1$, 171-191.

Glewen, William, Heuwetter, David, Foster, David, Andrie, Michael, \& Krieger, Roger (2012). Analysis of Deviations from Steady State Performance During Transient Operation of a Light Duty Diesel Engine. SAE Int. J. Engines, 5(3), 909-922.

Grahn, Markus. (2012). Diesel Engine Modeling for Engine Management System Development. Li-centiate Thesis.

Grahn, Markus, Johansson, Krister \& McKelvey, Tomas. (2013). A Diesel Engine Management System Strategy for Transient Engine Operation. 7th IFAC Symposium on Advances in Au-tomotive Control.

Grahn, Markus, Johansson, Krister \& McKelvey, Tomas. (2014a). A Transient Diesel EMS Strategy for Online Implementation. 2014 IFAC World Congress, August.

Grahn, Markus, Johansson, Krister, \& McKelvey, Tomas. 2014. Data-driven emission model structures for diesel engine management system development. International Journal of Engine Research, http://dx.doi.org/10.1177/1468087413512308.

Heywood, John B. (1988). Internal Combustion Engine Fundamentals. NewYork: McGraw-Hill.

Knafl, Alexander, Hagena, Jonathan R., Filipi Zoran S. \& Assanis, Dennis N. (2005). Dual-Use Engine Calibration: Leveraging Modern Technologies to Improve Performance - Emissions Tradeoff. SAE Technical Paper 2005-01-1549.

Montgomery D. T. and Reitz R. D. (2000). Optimization of Heavy-Duty Diesel Engine Operationg Parameters Using A Response Surface Method. SAE Technical Paper 2000-01-1962.

Montgomery, Douglas C. (2009). Design and Analysis of Experiments (7 edition). John Wiley \& Sons, Inc, New York. 
Nozaki, Yusuke, Fukuma, Takao \& Tanaka, Kazuo. (2005). Development of a Rulebased Calibration Method for Diesel Engines. SAE Technical Paper 2005-010044.

Qiang, Han, Fuyuan, Yang, Ming, Zhou \& Minggao, Ouyang. (2004). Study on Modeling Method for Common Rail Diesel Engine Calibration and Optimization. SAE Technical Paper 2004-01-0426.

Rao, Harish S., Cohen, A. I., Tennant, J. A. \& Van Voorhies, K. L. (1979). Engine Contro Optimization Via Nonlinear Programming. SAE Technical Paper 790177.

Rask, Eric \& Sellnau, Mark. (2004). Simulation-Based Engine Calibration: Tools, Techniques, and Applications. SAE Technical Paper 2004-01-1264.

Rishavy, E., Hamilton, S., Ayers, J. \& Keane, M. (1977). Engine Control Optimization for Best Fuel Economy with emission Constraints. SAE Technical Paper 770075.
Robert Bosch GmbH (2003). Electronic Diesel Control EDC: Bosch Technical Instruction. Cambridge, USA: Bentley Publishers.

Schmitz, G., Oligschl"ager, U. \& Eifles, G. (1994). Automated System for Optimized Calibration of Engine Management Systems. SAE Technical Paper 940151.

Sequenz, Heiko, Mrosek, Matthias, Zydek, Simon \& Isermann, Rolf. (2011). Model Based Optimisation of a Step in Acceleration for a CR-Diesel Engine. In Proceedings of the 6th IFAC Symposium Advances in Automotive Control, pages 13016-13021.

Timothy, V. Johnson, (2012). Vehicular Emissions in Review. SAE Int. J. Engines, 5(2), 216-234.

Wahlström, J. (2009). Control of EGR and VGT for Emission Control and Pumping Work Mini-mization in Diesel Engines. PhD thesis, Link oping University. 